\title{
Extended Weibull log-logistic distribution
}

T. H. M. Abouelmagd ${ }^{\mathrm{a}, *}$, Mohammed S. Hamed ${ }^{\mathrm{a}}$, Jehan. A. Almamy ${ }^{\mathrm{a}}$, M. Masoom Alib ${ }^{\mathrm{b}}$, Haitham M. Yousof ${ }^{\mathrm{c}}$, Mustafa Ç. Korkmaz ${ }^{d}$

a Management Information System Department, Taibah University, Saudi Arabia.

${ }^{b}$ Department of Mathematical Sciences, Ball State University, Muncie, USA.

${ }^{c}$ Department of Statistics, Mathematics and Insurance, Benha University, Egypt.

${ }^{d}$ Department of Measurement and Evaluation, Artvin Çoruh University, Artvin, Turkey.

\begin{abstract}
A new distribution called the Weibull Generalized log logistic distribution is introduced along with a simple physical motivation. Several of its statistical properties are derived. Three applications are provided to illustrate the importance of the new distribution. The new distribution is shown to be better that other important competitive models via three applications. The method of maximum likelihood is used to estimate the unknown parameters.
\end{abstract}

Keywords: Log-logistic distribution, Burr XII distribution, maximum likelihood, generating function, moments.

2010 MSC: 62E05, 62F10.

(C)2019 All rights reserved.

\section{Introduction and motivation}

[5] has suggested a number of forms of cumulative distribution functions (CDFs) which might be useful for fitting data. [7] devoted special attention to one of these forms, denoted by Burr type XII (BXII), whose $\mathrm{CDF}$ is given as

$$
\mathrm{G}_{(\mathrm{a}, \mathrm{b})}^{\mathrm{BXII}}(x)=1-\left.\left(1+x^{\mathrm{a}}\right)^{-b}\right|_{(x>0, a>0, b>0)} .
$$

Both $a$ and $b$ are shape parameters. Location and scale parameters can easily be introduced to make $\mathrm{G}_{(\mathrm{a}, \mathrm{b})}(\mathrm{x})$ a four-parameter distribution. The log-logistic (LL) distribution has appeared in the literature under different forms, the simplest one can easily be derived from $G_{(a, b)}(x)$ as a special case when $b=1$ so the CDF of the LL can be given as

$$
\mathrm{G}_{(\mathrm{a})}^{\mathrm{LL}}(x)=1-\left(1+\chi^{\mathrm{a}}\right)^{-1}
$$

\footnotetext{
*Corresponding author

Email addresses: tabouelmagd@taibahu.edu.sa (T. H. M. Abouelmagd), moswilem@gmail.com (Mohammed S. Hamed), handiquelaba@gmail.com (Jehan. A. Almamy), mali@bsu.edu (M. Masoom Ali), haitham.yousof@fcom.bu.edu.eg (Haitham M. Yousof), mcagatay@artvin.edu.tr (Mustafa Ç. Korkmaz)
}

doi: $10.22436 /$ jnsa.012.08.03

Received: 2018-12-20 Revised: 2019-02-14 Accepted: 2019-02-28 
The corresponding probability density function (PDF) of (1.1) is given by

$$
g_{(a)}(x)=a x^{a-1}\left(1+x^{a}\right)^{-2} .
$$

The hazard rate function (HRF) corresponding to (1.1) is

$$
h_{(a)}^{L L}(x)=a x^{a-1}\left(1+x^{a}\right)^{-1} .
$$

Based on [10] and using (1.1), then the CDF of the Weibull generalized log-logistic (WGLL) model is defined by

$$
F(x)=1-\left.\exp \left\{-\left[\left(1+x^{a}\right)^{\theta}-1\right]^{\beta}\right\}\right|_{(x>0, a>0, \beta>0, \theta>0)}
$$

and its corresponding PDF is given by

$$
f(x)=\beta \theta a x^{a-1}\left(1+x^{a}\right)^{\theta-1}\left[\left(1+x^{a}\right)^{\theta}-1\right]^{\beta-1} \exp \left\{-\left[\left(1+x^{a}\right)^{\theta}-1\right]^{\beta}\right\},
$$

where $\beta$ and $\theta$ are two additional shape parameters. From Figure 1, we conclude that the the PDF of the WGLL model can be bimodal or left skewed. In addition to the HRF can be unimodal, bathtub, constant, decreasing or increasing.
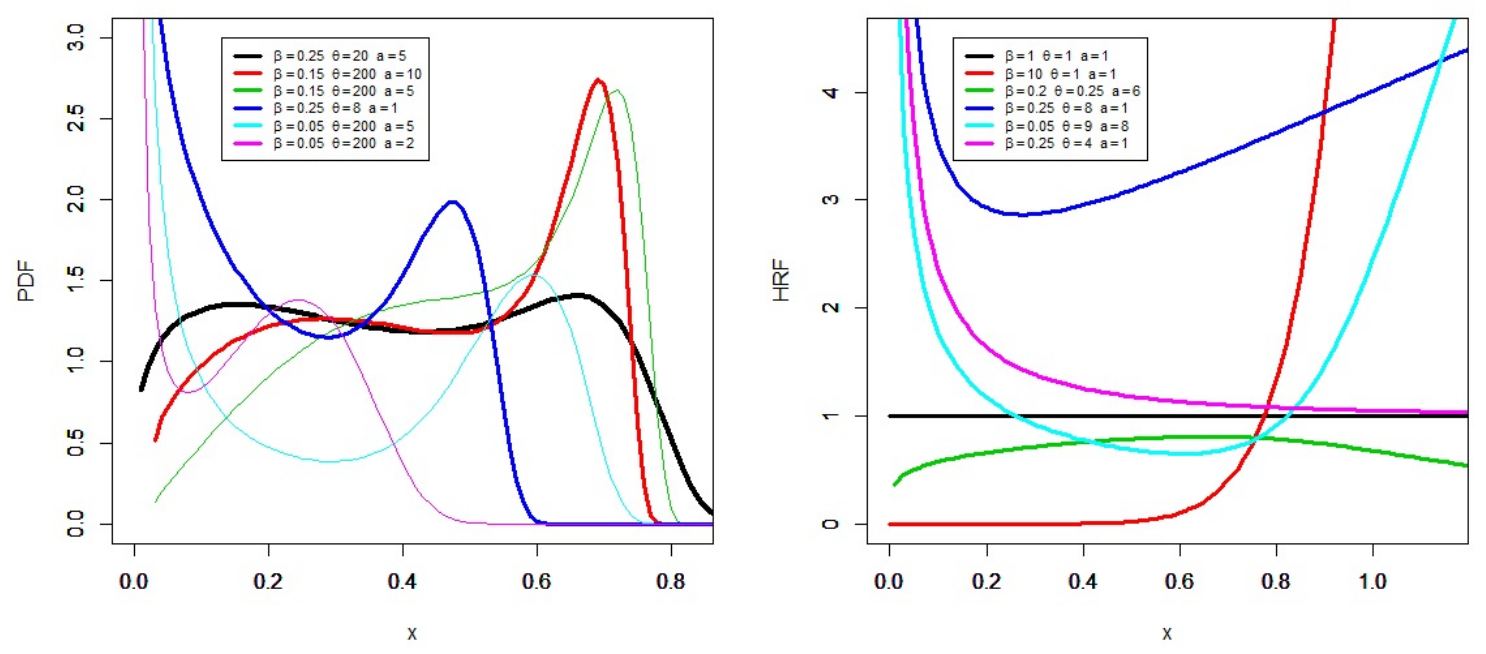

Figure 1: Plots of PDF (left) and HRF (right) for the new model.

In this work, we study the WGLL model and give a sufficient description of its mathematical properties. The new model is motivated by its important flexibility in applications (see Section 4). By means of two applications, it is noted that the WGLL model provides better fits than nine competitive models. Following [10], the PDF (1.3) of the WGLL model can be expressed as

$$
f(x)=\sum_{r=0}^{\infty} v_{r} g_{[a,(1+r)]}(x),
$$

which will be used below for deriving the ordinary moment, moment generating function and incomplete moment for the new model, where

$$
g_{[a,(1+r)]}(x)=(1+r) a x^{a-1}\left(1+x^{a}\right)^{-2-r}
$$


is the LL density with parameters $a$ and $(1+r), v_{r}=-w_{r}$ and

$$
w_{r}=\sum_{i, j, k=0}^{\infty} \frac{(-1)^{i+j+k+r}}{i ! r !}\left(\begin{array}{c}
i \beta \\
j
\end{array}\right)\left(\begin{array}{c}
\theta(j-i \beta) \\
k
\end{array}\right)\left(\begin{array}{c}
1+k \\
r
\end{array}\right) .
$$

Similarly, the CDF (1.2) of $X$ can be expressed in the mixture form

$$
F(x)=\sum_{r=0}^{\infty} v_{r} G_{[a,(1+r)]}(x),
$$

where

$$
\mathrm{G}_{[\mathrm{a},(1+\mathrm{r})]}(\mathrm{x})=1-\left(1+\mathrm{x}^{\mathrm{a}}\right)^{-(1+\mathrm{r})}
$$

is the LL CDF with parameters $a$ and $(1+r)$. A physical interpretation of the WGLL distribution can be shown as follows: suppose that we have a lifetime random variable (r.v.), $Z$ having BXII distribution. The generalized ratio

$$
\left\{1-\left[1-\mathrm{G}_{(\mathrm{a})}(\mathrm{x})\right]^{\Theta}\right\} /\left[1-\mathrm{G}_{(\mathrm{a})}(\mathrm{x})\right]^{\Theta}
$$

that an individual (or component) following the lifetime $Z$ will die (fail) at time $t$ is $-1+\left(1+x^{a}\right)^{\theta}$. Consider that the variability of this ratio of death is represented by the r.v. $X$ and assume that it follows the Weibull model with shape $\gamma$. We can write

$$
\operatorname{Pr}(Z \leqslant x)=\operatorname{Pr}\left(x \leqslant\left(1+x^{a}\right)^{\theta}-1\right)=F(x),
$$

which is given by the CDF (1.2).

\section{Mathematical properties}

The $\mathrm{n}^{\text {th }}$ ordinary moment of $X$ is given by

$$
\mu_{n}^{\prime}=\mathbf{E}\left(X^{n}\right)=\int_{-\infty}^{\infty} x^{n} f(x) d x
$$

Then, we obtain

$$
\mu_{n}^{\prime}=\left.\sum_{r=0}^{\infty} v_{r}(1+r) B\left(1+\frac{n}{a},(1+r)-\frac{n}{a}\right)\right|_{(n<(1+r) a)},
$$

where

$$
B(a, b)=\int_{0}^{\infty} t^{a-1}(1+t)^{-(a+b)} d t
$$

is the beta function of the second type. By setting $n=1$ in (2.1), we get the mean of $X$. The last integration is computed numerically for the new distribution (see Table 1). The skewness $(\mathrm{SK}(X))$ and kurtosis $(\mathrm{KU}(\mathrm{X})$ ) measures can be calculated from the ordinary moments using well-known relationships. The mean $\left(\mu_{1}^{\prime}\right)$, variance $(\mathrm{V}(\mathrm{X}))$, skewness and kurtosis of the WGLL distribution are computed numerically for some selected values of $\beta, \theta$ and a using the R software. The SK(X) of the WGLL distribution can range in the interval $(-0.92,58102)$, whereas the $\mathrm{KU}(X)$ of the WGLL distribution varies in the interval $(2.7,33758637)$ also the mean of $X$ decreases as $\theta$ increases (see Table 1 ).

The moment generating function (MGF) $M_{X}(t)=E\left(e^{t X}\right)$ of $X$ can be derived as

$$
M_{X}(t)=\left.\sum_{r, n=0}^{\infty} \frac{t^{n}}{n !} v_{r}(1+r) B\left(1+\frac{n}{a},(1+r)-\frac{n}{a}\right)\right|_{(n<(1+r) a)}
$$


Table 1: $\mu_{1}^{\prime}, \mathrm{V}(\mathrm{X}), \mathrm{SK}(\mathrm{X})$, and $\mathrm{KU}(\mathrm{X})$ of the WGLL distribution.

\begin{tabular}{|ccc|cccc|}
\hline$\beta$ & $\theta$ & $\mathrm{a}$ & $\mu_{1}^{\prime}$ & $\mathrm{V}(\mathrm{X})$ & $\mathrm{SK}(\mathrm{X})$ & $\mathrm{KU}(\mathrm{X})$ \\
\hline 0.5 & 1.5 & 1 & 0.86409 & 2.073985 & 3.657481 & 24.44979 \\
& 3 & & 0.30431 & 0.1628785 & 2.187074 & 9.125955 \\
& 6 & & 0.131019 & 0.025103 & 1.731804 & 6.20816 \\
& 10 & & 0.0743545 & 0.00756 & 1.582538 & 5.420255 \\
& 20 & & 0.0357083 & 0.001663 & 1.480515 & 4.924579 \\
& 50 & & 0.01395 & 0.0002469 & 1.446065 & 5.068848 \\
& 100 & & 0.006921 & $6.022126 \times \mathrm{e}^{-5}$ & 1.169008 & 6.268174 \\
\hline 1.5 & 1.5 & 0.75 & 0.4045834 & 0.2689907 & 0.408191 & 2.495388 \\
& 3 & & 0.0983878 & 0.02162491 & 0.5945535 & 2.279755 \\
& 6 & & 0.02743297 & 0.002281478 & 0.8825485 & 2.605601 \\
& 10 & & 0.011167 & 0.00046921 & 1.143081 & 3.229745 \\
& 20 & & 0.003396 & $4.8555 \times \mathrm{e}^{-5}$ & 1.114203 & 3.4094 \\
& 40 & & 0.0010512 & $1.981937 \times \mathrm{e}^{-6}$ & 7.143419 & 57.9362 \\
\hline 2 & 0.75 & 0.25 & 432.065 & 302558.6 & $-\mathbf{0 . 9 2 7 6 4 1}$ & 3.05917 \\
& 1 & & 11.6317 & 1016.245 & 0.5896279 & 2.71225 \\
& 1.5 & & 0.15813 & 0.9557223 & 2.323566 & 9.883611 \\
& 3 & & 0.00033 & $4.551032 \times \mathrm{e}^{-5}$ & 7.902308 & 87.50395 \\
& 6 & & $1.5826 \times \mathrm{e}^{-6}$ & $1.35496 \times \mathrm{e}^{-8}$ & 18.35436 & 337.4141 \\
& 9 & & $1.585 \times \mathrm{e}^{-13}$ & $1.3575 \mathrm{e}^{-15}$ & $\mathbf{5 8 1 0 2 . 1 8}$ & 33758637 \\
\hline
\end{tabular}

The $\mathrm{n}^{\text {th }}$ incomplete moment $\left(\mathbf{I}_{\mathfrak{n}}(\mathrm{t})\right)$ of $X$ can be expressed as

$$
\mathbf{I}_{n}(t)=\int_{-\infty}^{t} x^{n} f(x) d x=\left.\sum_{r=0}^{\infty} v_{r}(1+r) B\left(t^{a} ; 1+\frac{n}{a},(1+r)-\frac{n}{a}\right)\right|_{(n<(1+r) a)},
$$

where

$$
B(q ; a, b)=\int_{0}^{q} t^{a-1}(1+t)^{-(a+b)} d t
$$

is the incomplete beta function of the second type. When $n=1$ we have $1^{\text {st }}$ incomplete moment. The main applications of the $1^{\text {st }}$ incomplete moment refer to the mean deviations and the Bonferroni and Lorenz curves which are very useful in economics, reliability, demography, insurance, and medicine.

The $(\mathrm{s}, \mathrm{r})^{\text {th }}$ PWM of $X$ following the WGLL model, say $\lambda_{s, r}$, is formally defined by

$$
\lambda_{s, r}=E\left\{X^{s} F(X)^{r}\right\}=\int_{-\infty}^{\infty} x^{s} F(x)^{r} f(x) d x
$$

The $(\mathrm{s}, \mathrm{r})^{\mathrm{th}} \mathrm{PWM}$ of $\mathrm{X}$ can be expressed as

$$
\lambda_{s, r}=\left.\sum_{r=0}^{\infty} v_{r}(1+r) B\left(\frac{s}{a}+1,(1+r)-\frac{s}{a}\right)\right|_{(s<(1+r) a)}
$$

where

$$
v_{r}=\beta \theta \sum_{m, i, j, k=0}^{\infty} \frac{(-1)^{m+i+j+k}(m+1)^{i}}{m ! i !}(r)_{k}\left(\begin{array}{c}
1+k \\
r
\end{array}\right)\left(\begin{array}{c}
(1+i) \beta-1 \\
j
\end{array}\right)\left(\begin{array}{c}
\theta[-(1+i) \beta+j]-1 \\
k
\end{array}\right),
$$


and

$$
\left(\tau_{1}\right)_{\tau_{2}}=\tau_{1}\left(\tau_{1}-1\right) \cdots\left(1+\tau_{1}-\tau_{2}\right)
$$

is the descending factorial and $\tau_{2}$ is a positive integer.

Let $X_{1}, X_{2}, \ldots, X_{n}$ be a random sample (RS) from the WGLL distribution and let $X_{1: n}, \ldots, X_{n: n}$ be the corresponding order statistics. The PDF of $i^{\text {th }}$ order statistic, say $X_{i: n}$, can be written as

$$
f_{i: n}(x)=B^{-1}(i, n-i+1) f(x) \sum_{j=0}^{n-i}(-1)^{j}\left(\begin{array}{c}
n-i \\
j
\end{array}\right)[F(x)]^{j+i-1},
$$

where $B(\cdot, \cdot)$ is the beta function. Inserting (1.2) and (1.3) in equation (2.2) and using a power series expansion, we have

$$
[F(x)]^{j+i-1} f(x)=\sum_{r=0}^{\infty} c_{r} g_{[a,(1+r)]}(x),
$$

where

$$
\begin{aligned}
c_{r}= & \beta \theta \sum_{m, l, w, k=0}^{\infty} \sum_{j=0}^{n-i} \frac{(-1)^{m+l+w+k+j}(m+1)^{l}}{m ! l ! B(i, n-i+1)}(j+i-1)_{k} \\
& \times\left(\begin{array}{c}
n-i \\
j
\end{array}\right)\left(\begin{array}{c}
1+k \\
j+i-1
\end{array}\right)\left(\begin{array}{c}
(1+i) \beta-1 \\
w
\end{array}\right)\left(\begin{array}{c}
\theta[-\beta(l+1)+w]-1 \\
k
\end{array}\right),
\end{aligned}
$$

and the PDF of $X_{i: n}$ can be expressed as

$$
f_{i: n}(x)=\sum_{j=0}^{n-i} \sum_{r=0}^{\infty} \frac{(-1)^{j}}{B(i, n-i+1)}\left(\begin{array}{c}
n-i \\
j
\end{array}\right) c_{r} g_{[a,(1+r)]}(x),
$$

and the $\mathrm{q}^{\text {th }}$ moments of $X_{i: n}$ can be expressed as

$$
\mathbf{E}\left(X_{i: n}^{\mathrm{q}}\right)=\left.\sum_{r=0}^{\infty} c_{r} g(1+r) B\left(1+\frac{q}{a},(1+r)-\frac{q}{a}\right)\right|_{(q<(1+r) a)} .
$$

The $\mathrm{n}^{\text {th }}$ moment of the reversed residual life, say

$$
\omega_{n}(t)=E\left[\left.(t-X)^{n}\right|_{(X \leqslant t, t>0, n=1,2, \ldots)}\right]
$$

uniquely determines $F(x)$. We obtain

$$
\omega_{n}(t)=F^{-1}(t) \int_{0}^{t}(t-x)^{n} d F(x) .
$$

Then, the $\mathrm{n}^{\text {th }}$ moment of the reversed residual life of $X$ becomes

$$
\omega_{n}(t)=F^{-1}(t) \sum_{r=0}^{\infty} v_{r}^{(\omega)}(1+r) B\left(t^{a} ;(1+r)-\frac{n}{a}, 1+\frac{n}{a}\right),
$$

where

$$
v_{r}^{(\omega)}=v_{r} \sum_{r=0}^{n}(-1)^{r}\left(\begin{array}{l}
n \\
r
\end{array}\right) t^{n-r}
$$

\section{Parameter estimation}

Consider the estimation of the unknown parameters $(\beta, \theta, a)$ of the WGLL model from the complete data sets by the maximum likelihood (ML) method. Suppose that $x_{1}, \ldots, x_{n}$ be a RS from the WGLL 
model with parameter vector $\Theta=(\beta, \theta, a)^{\top}$. Then the log-likelihood function $\left(\ell_{n}(\Theta)\right)$ for $\Theta$ is given by

$$
\begin{aligned}
\ell_{n}(\Theta)= & n \log \beta+n \log \theta+n \log a+(\theta-1) \sum_{i=1}^{n} \log \left(1+x_{i}^{a}\right) \\
& +(\beta-1) \sum_{i=1}^{n} \log \left[\left(1+x_{i}^{a}\right)^{\theta}-1\right]-\sum_{i=1}^{n}\left[\left(1+x_{i}^{a}\right)^{\theta}-1\right]^{\beta},
\end{aligned}
$$

the above $\ell_{n}(\Theta)$ can be maximized numerically via SAS (PROC NLMIXED) or R (optim) or Ox program (via sub-routine MaxBFGS), among others. The components of the score vector

$$
\mathbf{U}(\Theta)=\frac{\partial \ell}{\partial \Theta}=\left(\frac{\partial \ell_{n}(\Theta)}{\partial \beta}, \frac{\partial \ell_{n}(\Theta)}{\partial \theta}, \frac{\partial \ell_{n}(\Theta)}{\partial a}\right)^{\top}
$$

are easy to be derived.

\section{Applications}

We provide three applications to illustrate the importance, potentiality and flexibility of the WGLL model. For these data, we compare the WGLL distribution with BXII, WLL, Marshall-Olkin BXII (MOBXII), Topp Leone BXII (TLBXII), Zografos-Balakrishnan BXII (ZBBXII), Five Parameters beta BXII (FBBXII), BBXII, B exponentiated BXII (BEBXII), Five Parameters Kumaraswamy BXII (FKwBXII) and KwBXII distributions given in $[2,3,8,9]$. The three data sets are given in the Appendix.

The total time test (TTT) plot (see [1]) is an important graphical approach to verify whether the data can be applied to a specific distribution or not, the empirical version of the TTT plot is given by plotting

$$
T(r / n)=\left[\sum_{i=1}^{r} y_{i: n}+(n-r) y_{r: n}\right] / \sum_{i=1}^{n} y_{i: n}
$$

against $r / n$, where $r=1, \ldots, n$ and $y_{i: n}(i=1, \ldots, n)$ are the order statistics of the sample. [1] showed that the HRF is constant if the TTT plot is graphically presented as a straight diagonal, the HRF is increasing (or decreasing) if the TTT plot is concave (or convex). The HRF is U-shaped (bathtub) if the TTT plot is firstly convex and then concave, if not, the HRF is unimodal. The TTT plots the three real data sets are presented in Figure 2 and these plots indicate that the empirical HRFs of data sets I, II are increasing and bathtub for data set III. We consider the following goodness-of-fit statistics: the Akaike information criterion (AIC), Bayesian information criterion (BIC), Hannan-Quinn information criterion (HQIC), and consistent Akaike information criterion (CAIC), where

$$
\begin{aligned}
& A I C=-2 \ell(\widehat{\Theta})+2 k, \\
& B I C=-2 \ell(\widehat{\Theta})+k \log (n),
\end{aligned}
$$

and

$$
\mathrm{CAIC}=-2 \ell(\widehat{\Theta})+2 k n /(n-k-1),
$$

where $k$ is the number of parameters, $n$ is the sample size, and $-2 \ell(\widehat{\Theta})$ is the maximized log-likelihood. Generally, the smaller these statistics are, the better the fit. Based on the values in Tables 3, 5, and 7 and Figures 3-6 the WGLL model provides the best fits as compared to BXII and other models in the applications with small values for BIC, AIC, CAIC, and HQIC. 

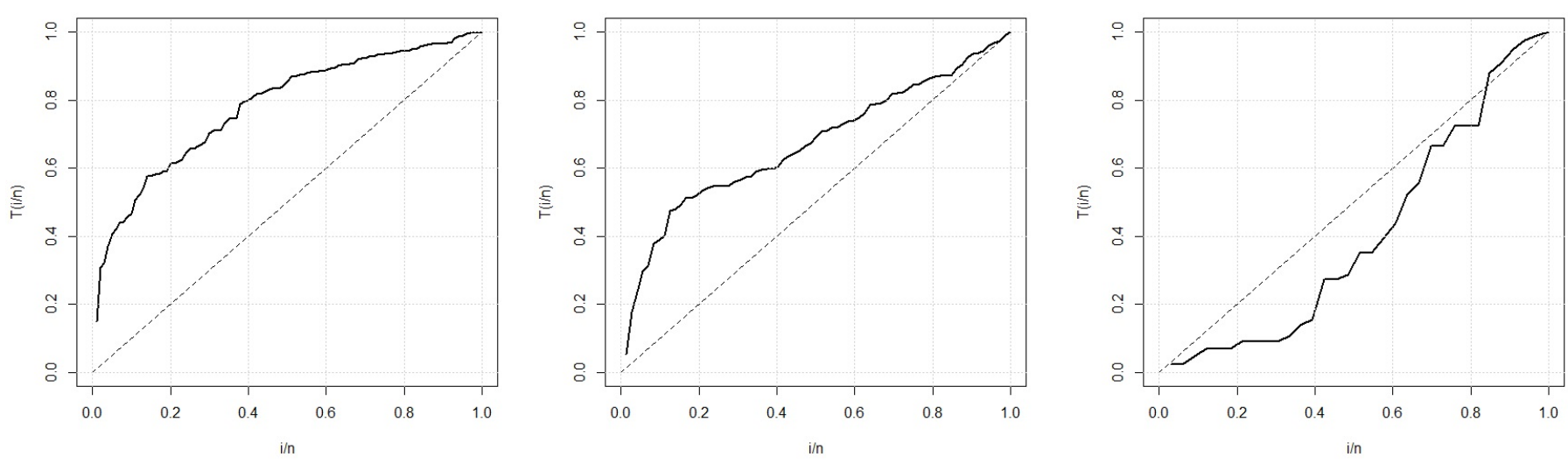

Figure 2: TTT plots for the first (left), second (middle) and third (right) data sets.

Table 2: MLEs, standard errors, and confidence interval (in parentheses) for the data set I.

\begin{tabular}{|c|c|}
\hline Model & Estimates \\
\hline $\operatorname{BXII}(\alpha, \beta)$ & $\begin{array}{c}5.941,0.187 \\
(1.279),(0.044) \\
(3.43,8.45),(0.10,0.27)\end{array}$ \\
\hline $\operatorname{MOBXII}(\alpha, \beta, \gamma)$ & $\begin{array}{c}1.192,4.834,838.73 \\
(0.952),(4.896),(229.34) \\
(0,3.06),(0,14.43),(389.22,1288.24)\end{array}$ \\
\hline $\operatorname{TLBXII}(\alpha, \beta, \gamma)$ & $\begin{array}{c}1.350,1.061,13.728 \\
(0.378),(0.384),(8.400) \\
(0.61,2.09),(0.31,1.81),(0,30.19)\end{array}$ \\
\hline $\operatorname{KwBXII}(\lambda, \theta, \alpha, \beta)$ & $\begin{array}{c}48.103,79.516,0.351,2.730 \\
(19.348),(58.186),(0.098),(1.077) \\
(10.18,86.03),(0,193.56),(0.16,0.54),(0.62,4.84)\end{array}$ \\
\hline $\operatorname{BBXII}(\lambda, \theta, \alpha, \beta)$ & $\begin{array}{c}\text { 359.683, 260.097, } 0.175,1.123 \\
(57.941),(132.213),(0.013),(0.243) \\
(246.1,473.2),(0.96,519.2),(0.14,0.20),(0.65,1.6)\end{array}$ \\
\hline $\operatorname{BEBXII}(\lambda, \theta, \alpha, \beta, \gamma)$ & $\begin{array}{c}0.381,11.949,0.937,33.402,1.705 \\
(0.078),(4.635),(0.267),(6.287),(0.478) \\
(0.23,0.53),(2.86,21),(0.41,1.5),(21,45),(0.8,2.6)\end{array}$ \\
\hline $\operatorname{FBBXII}(\lambda, \theta, \alpha, \beta, \gamma)$ & $\begin{array}{c}0.421,0.834,6.111,1.674,3.450 \\
(0.011),(0.943),(2.314),(0.226),(1.957) \\
(0.4,0.44),(0.2 .7),(1.57,10.7),(1.23,2.1),(0,7)\end{array}$ \\
\hline $\operatorname{FKwBXII}(\lambda, \theta, \alpha, \beta, \gamma)$ & $\begin{array}{c}0.542,4.223,5.313,0.411,4.152 \\
(0.137),(1.882),(2.318),(0.497),(1.995) \\
(0.3,0.8),(0.53,7.9),(0.9,9),(0,1.7),(0.2,8)\end{array}$ \\
\hline $\operatorname{ZBBXII}(\lambda, \alpha, \beta)$ & $\begin{array}{c}123.101,0.368,139.247 \\
(243.011),(0.343),(318.546) \\
(0,599.40),(0,1.04),(0,763.59)\end{array}$ \\
\hline $\operatorname{WLL}(\beta, a)$ & $\begin{array}{c}1.116,0.71 \\
(6.5),(4.12) \\
(0,16.1),(0,8.94)\end{array}$ \\
\hline $\operatorname{WGLL}(\beta, \theta, a)$ & $\begin{array}{c}3.74,0.52,0.97 \\
(2.79),(0.301),(1.001) \\
(0,9.34),(0,1.12),(0,2.97)\end{array}$ \\
\hline
\end{tabular}




Table 3: AIC, BIC, CAIC, and HQIC values for the data s
\begin{tabular}{|l|c|}
\hline Model & AIC, BIC, CAIC, HQIC \\
\hline BXII & $382.94,388.15,383.06,385.05$ \\
MOBXII & $305.78,313.61,306.03,308.96$ \\
TLBXII & $323.52,331.35,323.77,326.70$ \\
KwBXII & $303.76,314.20,304.18,308.00$ \\
BBXII & $305.64,316.06,306.06,309.85$ \\
BEBXII & $305.82,318.84,306.46,311.09$ \\
FBBXII & $304.26,317.31,304.89,309.56$ \\
FKwBXII & $305.50,318.55,306.14,310.80$ \\
ZBBXII & $302.96,310.78,303.21,306.13$ \\
WLL & $510.69,515.91,510.82,512.84$ \\
WGLL & $\mathbf{2 8 8 . 7 2 , 2 9 6 . 5 4 , 2 8 8 . 9 , 2 9 1 . 8 8}$ \\
\hline
\end{tabular}

Table 4: MLEs, standard errors, and confidence interval (in parentheses) for the data set II.

\begin{tabular}{|c|c|}
\hline Model & Estimates \\
\hline $\operatorname{BXII}(\alpha, \beta)$ & $\begin{array}{c}3.102,0.465 \\
(0.538),(0.077) \\
(2.05,4.16),(0.31,0.62)\end{array}$ \\
\hline $\operatorname{MOBXII}(\alpha, \beta, \gamma)$ & $\begin{array}{c}2.259,1.533,6.760 \\
(0.864),(0.907),(4.587) \\
(0.57,3.95),(0,3.31),(0,15.75)\end{array}$ \\
\hline $\operatorname{TLBXII}(\alpha, \beta, \gamma)$ & $\begin{array}{c}2.393,0.458,1.796 \\
(0.907),(0.244),(0.915) \\
(0.62,4.17),(0,0.94),(0.002,3.59)\end{array}$ \\
\hline $\operatorname{KwBXII}(\lambda, \theta, \alpha, \beta)$ & $\begin{array}{c}14.105,7.424,0.525,2.274 \\
(10.805),(11.850),(0.279),(0.990) \\
(0,35.28),(0.30 .65),(0,1.07),(0.33,4.21)\end{array}$ \\
\hline $\operatorname{BBXII}(\lambda, \theta, \alpha, \beta)$ & $\begin{array}{c}2.555,6.058,1.800,0.294 \\
(1.859),(10.391),(0.955),(0.466) \\
(0,6.28),(0,26.42),(0,3.67),(0,1.21) \\
\end{array}$ \\
\hline $\operatorname{BEBXII}(\lambda, \theta, \alpha, \beta, \gamma)$ & $\begin{array}{c}1.876,2.991,1.780,1.341,0.572 \\
(0.094),(1.731),(0.702),(0.816),(0.325) \\
(1.7,2.06),(0,6.4),(0.40,3.2),(0,2.9),(0,1.21)\end{array}$ \\
\hline $\operatorname{FBBXII}(\lambda, \theta, \alpha, \beta, \gamma)$ & $\begin{array}{c}0.621,0.549,3.838,1.381,1.665 \\
(0.541),(1.011),(2.785),(2.312),(0.436) \\
(0,1.7),(0,2.5),(0,9.3),(0,5.9),(0.8,4.5)\end{array}$ \\
\hline $\operatorname{FKwBXII}(\lambda, \theta, \alpha, \beta, \gamma)$ & $\begin{array}{c}0.558,0.308,3.999,2.131,1.475 \\
(0.442),(0.314),(2.082),(1.833),(0.361) \\
(0,1.4),(0,0.9),(0,3.1),(0,5.7),(0.76,2.2)\end{array}$ \\
\hline $\operatorname{WLL}(\beta, a)$ & $\begin{array}{c}0.785,1.254 \\
(0.00),(0.00) \\
-,-\end{array}$ \\
\hline $\operatorname{WGLL}(\beta, \theta, a)$ & $\begin{array}{c}0.921,0.31,3.3 \\
(0.2),(0.08),(1.13) \\
(0.52,1.32),(0.15,0.47),(1.1,5.5)\end{array}$ \\
\hline
\end{tabular}


Table 5: AIC, BIC, CAIC, and HQIC values for the data set II.

\begin{tabular}{|l|c|}
\hline \hline Model & AIC, BIC, CAIC, HQIC \\
\hline BXII & $209.60,214.15,209.77,211.40$ \\
MOBXII & $209.74,216.56,210.09,212.44$ \\
TLBXII & $211.80,218.63,212.15,214.52$ \\
KwBXII & $208.76,217.86,209.36,212.38$ \\
BBXII & $210.44,219.54,211.03,214.06$ \\
BEBXII & $212.10,223.50,213.00,216.60$ \\
FBBXII & $206.80,218.20,207.71,211.30$ \\
FKwBXII & $206.50,217.90,207.41,211.00$ \\
WLL & $270.44,274.98,270.60,272.23$ \\
WGLL & $\mathbf{2 0 3 . 8 6 , 2 1 0 . 6 9 , 2 0 4 . 2 2 , ~ 2 0 6 . 5 8 ~}$ \\
\hline
\end{tabular}

Table 6: MLEs, standard errors, and confidence interval (in parentheses) for the data set III.

\begin{tabular}{|c|c|}
\hline Model & Estimates \\
\hline $\operatorname{BXII}(\alpha, \beta)$ & $\begin{array}{c}58.711,0.006 \\
(42.382),(0.004) \\
(0,141.78),(0,0.01)\end{array}$ \\
\hline $\operatorname{MOBXII}(\alpha, \beta, \gamma)$ & $\begin{array}{c}11.838,0.078,12.251 \\
(4.368),(0.013),(7.770) \\
(0,141.78),(0,0.01),(0,27.48)\end{array}$ \\
\hline $\operatorname{TLBXII}(\alpha, \beta, \gamma)$ & $\begin{array}{c}0.281,1.882,50.215 \\
(0.288),(2.402),(176.50) \\
(0,0.85),(0,6.59),(0,396.16)\end{array}$ \\
\hline $\operatorname{KwBXII}(\lambda, \theta, \alpha, \beta)$ & $\begin{array}{c}9.201,36.428,0.242,0.941 \\
(10.060),(35.650),(0.167),(1.045) \\
(0,28.912),(0,106.30),(0,0.57),(0,2.99)\end{array}$ \\
\hline $\operatorname{BBXII}(\lambda, \theta, \alpha, \beta)$ & $\begin{array}{c}96.104,52.121,0.104,1.227 \\
(41.201),(33.490),(0.023),(0.326) \\
(15.4,176.8),(0,117.8),(0.6,0.15),(0.59,1.9)\end{array}$ \\
\hline $\operatorname{BEBXII}(\lambda, \theta, \alpha, \beta, \gamma)$ & $\begin{array}{c}0.087,5.007,1.561,31.270,0.318 \\
(0.077),(3.851),(0.012),(12.940),(0.034) \\
(0,0.3),(0,12.6),(1.5,1.6),(5.9,56.6),(0.3,0.4)\end{array}$ \\
\hline $\operatorname{FBBXII}(\lambda, \theta, \alpha, \beta, \gamma)$ & $\begin{array}{c}15.194,32.048,0.233,0.581,21.855 \\
(11.58),(9.867),(0.091),(0.067),(35.548) \\
(0,37.8),(12.7,51.4),(0.05,0.4),(0.45,0.7),(0,91.5)\end{array}$ \\
\hline $\operatorname{FKwBXII}(\lambda, \theta, \alpha, \beta, \gamma)$ & $\begin{array}{c}14.732,15.285,0.293,0.839,0.034 \\
(12.390),(18.868),(0.215),(0.854),(0.075) \\
(0,39.02),(0,52.27),(0,0.71),(0,2.51),(0,0.18)\end{array}$ \\
\hline $\operatorname{ZBBXII}(\lambda, \alpha, \beta, \gamma)$ & $\begin{array}{c}41.973,0.157,44.263 \\
(38.787),(0.082),(47.648) \\
(0,117.99),(0,0.32,)(0,137.65)\end{array}$ \\
\hline $\operatorname{WLL}(\beta, a)$ & $\begin{array}{c}1.069,0.224 \\
(0.00),(0.00) \\
-,-\end{array}$ \\
\hline $\operatorname{WGLL}(\beta, \theta, a)$ & $\begin{array}{c}1.55,0.1,2.08 \\
(0.319),(0.12),(2.21) \\
(0.95,2.15),(0,),(0,6.48)\end{array}$ \\
\hline
\end{tabular}


Table 7: AIC, BIC, CAIC, and HQIC values for the data set III.

\begin{tabular}{|l|c|}
\hline Model & AIC, BIC, CAIC, HQIC \\
\hline BXII & $328.20,331.19,328.60,329.19$ \\
MOBXII & $315.54,320.01,316.37,317.04$ \\
TLBXII & $316.26,320.73,317.09,317.76$ \\
KwBXII & $317.36,323.30,318.79,319.34$ \\
BBXII & $316.46,322.45,317.89,318.47$ \\
BEBXII & $317.58,325.06,319.80,320.09$ \\
FBBXII & $317.86,325.34,320.08,320.36$ \\
FKwBXII & $317.76,325.21,319.98,320.26$ \\
ZBBXII & $313.86,318.35,314.39,315.36$ \\
WLL & $378.82,381.79,379.27,379.84$ \\
WGLL & $\mathbf{3 1 2 . 3 7 , 3 1 6 . 8 6 , 3 1 3 . 1 9 , 3 1 3 . 8 8}$ \\
\hline
\end{tabular}
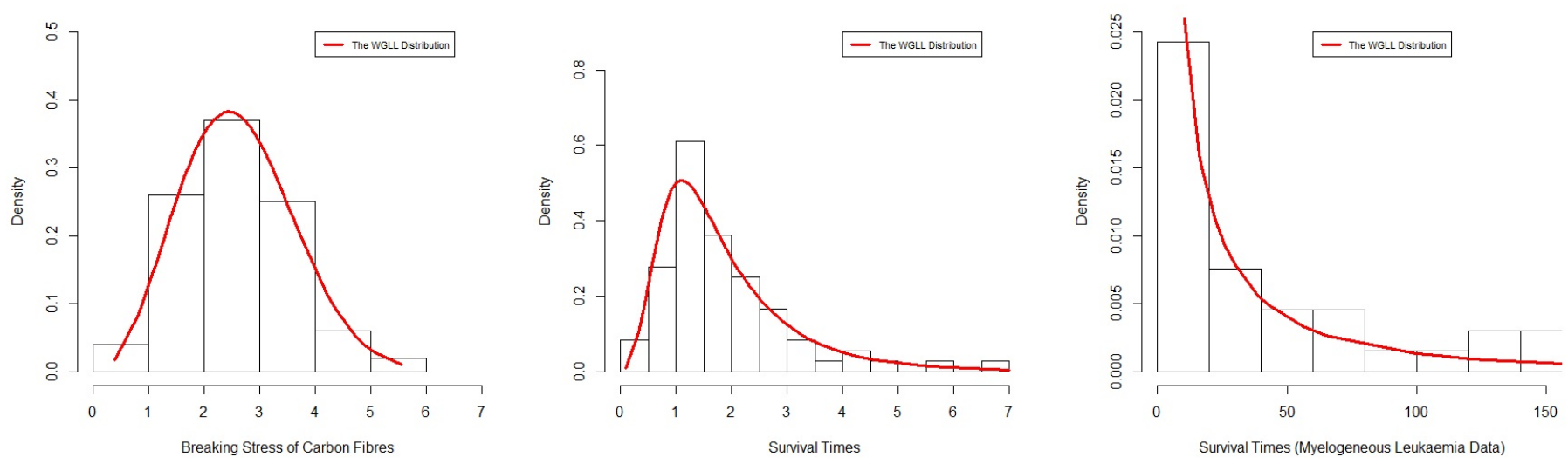

Figure 3: Estimated PDFs for the data sets.
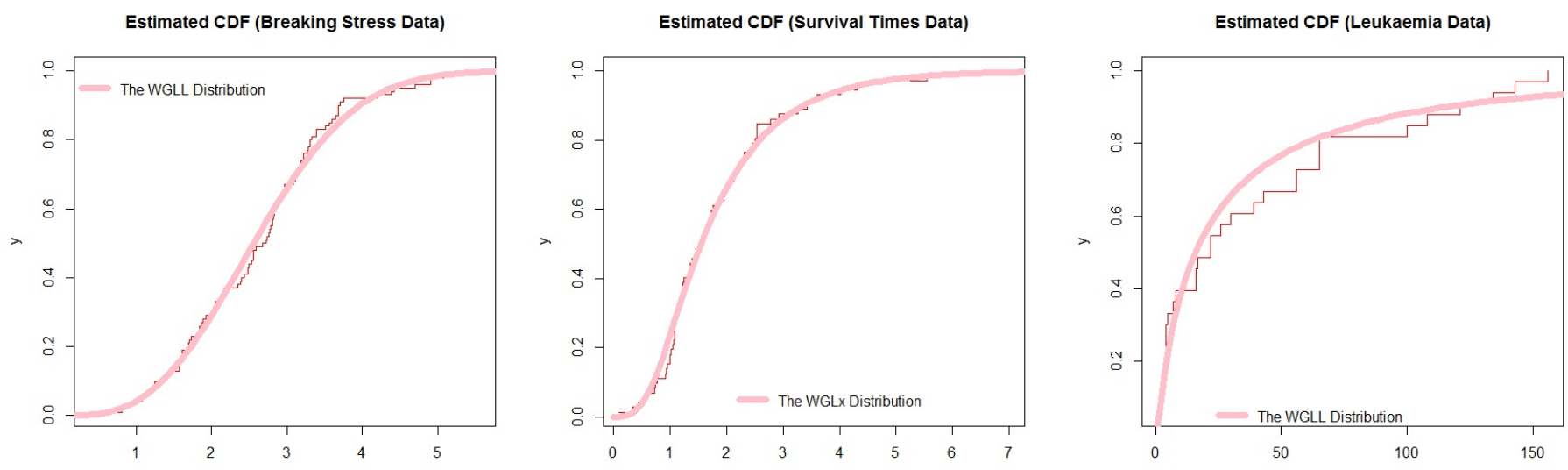

Figure 4: Estimated CDFs for the data sets. 

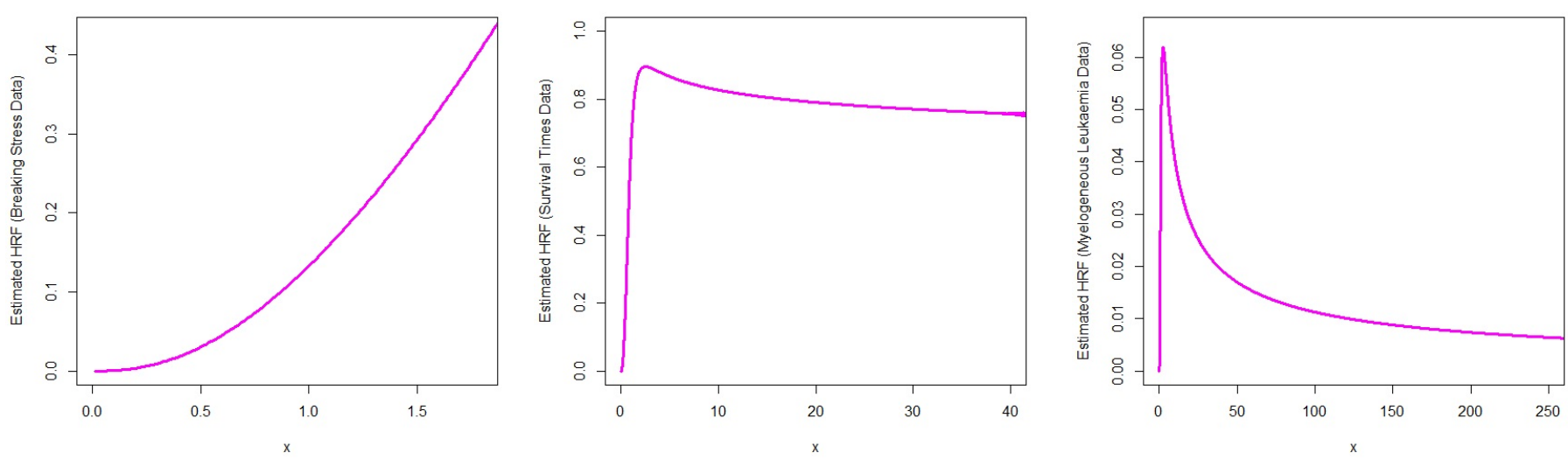

Figure 5: Estimated HRFs for the data sets.
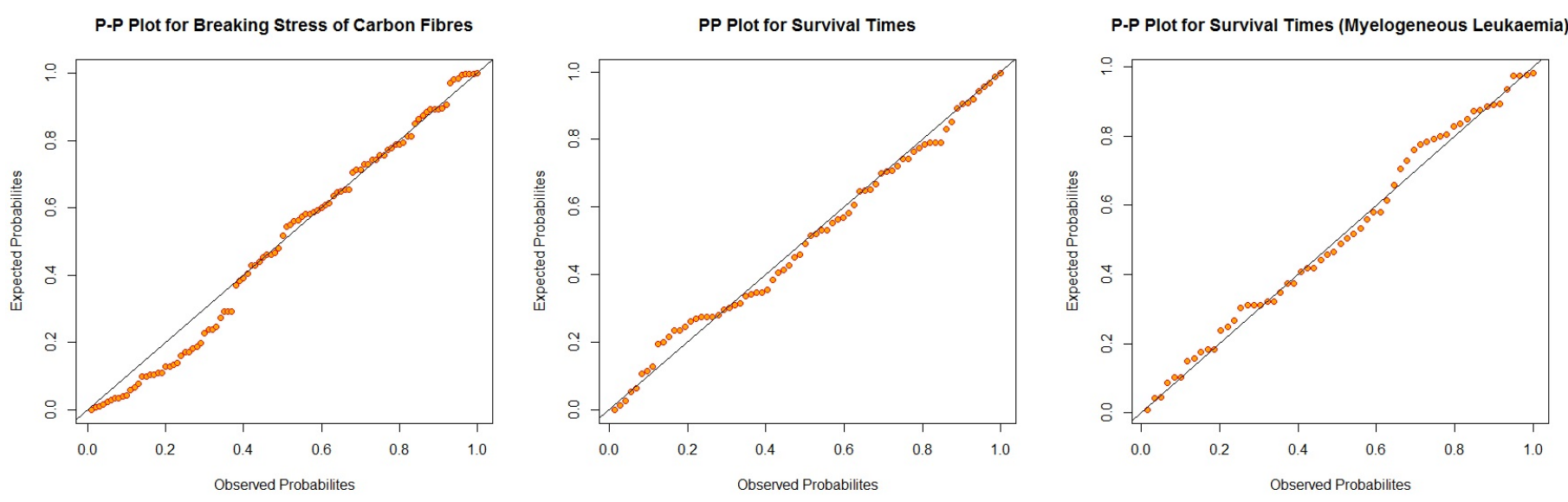

Figure 6: P-P plots.
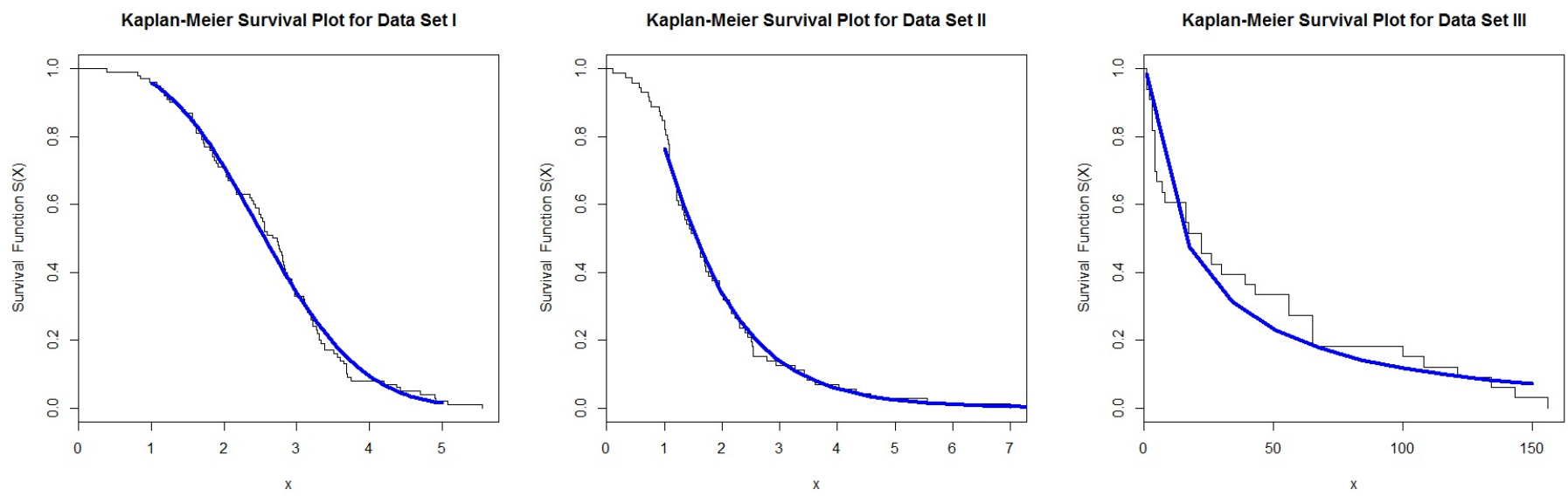

Figure 7: Kaplan-Meier Survival plots.

\section{Conclusions}

In this paper, we introduce a new continuous distribution with a strong physical motivation and applications via compounding the zero truncated Poisson distribution and a new continuous distribution 
called the Burr X Burr XII distribution. Some of its properties are derived. Four applications are provided with details to illustrate the importance of the new model. The new model is better that other nine competitive models via four applications. The method of maximum likelihood is used to estimate the unknown parameters. The new model provides adequate fits as compared to other related models in four applications with small values for AIC, BIC, CAIC and HQIC. The new model is much better than the Burr XII, Kumaraswamy Burr XII, Marshall-Olkin BXII, beta Burr XII, Topp Leone Burr XII, beta exponentiated Burr XII, Five parameter Kumaraswamy Burr XII, Five parameter beta Burr XII, Zografos-Balakrishnan Burr XII and Weibull log-logistic models in modeling the three data sets.

\section{References}

[1] M. V. Aarset, How to identify a bathtub hazard rate, IEEE Trans. Reliab., 36 (1987), 106-108. 4

[2] E. Altun, H. M. Yousof, S. Chakraborty, L. Handique, Zografos-Balakrishnan Burr XII distribution: regression modeling and applications, Int. J. Math. Stat., 19 (2018), 46-70. 4

[3] E. Altun, H. M. Yousof, G. G. Hamedani, A new log-location regression model with influence diagnostics and residual analysis, Facta Univ. Ser. Math. Inform., 33 (2018), 417-449. 4

[4] T. Bjerkedal, Acquisition of resistance in Guinea pigs infected with different doses of virulent tubercle bacilli, Amer. J. Hygiene, 72 (1960), 130-148. 5

[5] I. W. Burr, Cumulative frequency functions, Ann. Math. Statistics, 13 (1942), 215-232. 1

[6] M. D. Nichols, W. J. Padgett, A bootstrap control chart for Weibull percentiles, Quality Reliab. Eng. Int., 22 (2006), 141-151. 5

[7] R. N. Rodriguez, A Guide to the Burr type XII distributions, Biometrika, 64 (1977), 129-134. 1

[8] H. M. Yousof, E. Altun, T. G. Ramires, M. Alizadeh, M. Rasekhi, A new family of distributions with properties, regression models and applications, J. Stat. Manag. Syst., 21 (2018), 163-188. 4

[9] H. M. Yousof, E. Altun, M. Rasekhi, M. Alizadeh, G. G. Hamedani, M. M. Ali, A new lifetime model with regression models, characterizations and applications, Comm. Statist. Theory Methods, 2017 (2017), 23 pages. 4

[10] H. M. Yousof, M. Majumder, S. M. A. Jahanshahi, M. M. Ali, G. G. Hamedani, A new Weibull class of distributions: theory, characterizations and applications, J. Stat. Res. Iran, 15 (2018), 45-82. 1, 1

\section{Appendix}

Data set I: $\{0.98,5.56,5.08,0.39,1.57,3.19,4.90,2.93,2.85,2.77,2.76,1.73,2.48,3.68,1.08,3.22,3.75$, $3.22,3.70,2.74,2.73,2.50,3.60,3.11,3.27,2.87,1.47,3.11,4.42,2.40,3.15,2.67,3.31,2.81,2.56,2.17,4.91$, $1.59,1.18,2.48,2.03,1.69,2.43,3.39,3.56,2.83,3.68,2.00,3.51,0.85,1.61,3.28,2.95,2.81,3.15,1.92,1.84$, $1.22,2.17,1.61,2.12,3.09,2.97,4.20,2.35,1.41,1.59,1.12,1.69,2.79,1.89,1.87,3.39,3.33,2.55,3.68,3.19$, $1.71,1.25,4.70,2.88,2.96,2.55,2.59,2.97,1.57,2.17,4.38,2.03,2.82,2.53,3.31,2.38,1.36,0.81,1.17,1.84$, $1.80,2.05,3.65\}$ is called breaking stress data. This data set consists of 100 observations of breaking stress of carbon fibres (in Gba) given by [6].

Data setII: $\{0.1,0.33,0.44,0.56,0.59,0.72,0.74,0.77,0.92,0.93,0.96,1,1,1.02,1.05,1.07,07,1.08,1.08$, $1.08,1.09,1.12,1.13,1.15,1.16,1.2,1.21,1.22,1.22,1.24,1.3,1.34,1.36,1.39,1.44,1.46,1.53,1.59,1.6,1.63$, $1.63,1.68,1.71,1.72,1.76,1.83,1.95,1.96,1.97,2.02,2.13,2.15,2.16,2.22,2.3,2.31,2.4,2.45,2.51,2.53,2.54$, $2.54,2.78,2.93,3.27,3.42,3.47,3.61,4.02,4.32,4.58,5.55\}$ is called survival times in days of 72 guinea pigs infected with virulent tubercle bacilli, originally observed and reported by [4].

Data set III: $\{65,156,100,134,16,108,121,4,39,143,56,26,22,1,1,5,65,56,65,17,7,16,22,3,4$, $2,3,8,4,3,30,4,43\}$ is called leukaemia data. This real data set gives the survival times, in weeks, of 33 patients suffering from acute Myelogeneous Leukaemia. 